\title{
Padrões espaciais de índices socioeconômicos e sua relação com área verde de um centro urbano
}

As áreas verdes urbanas exercem inúmeras funções no meio ambiente natural, sobretudo no ambiente urbano, pois no contexto das cidades são importantes para o bem-estar humano. O objetivo desse trabalho foi estabelecer um índice sistemático a partir de análise de padrões espaciais de informações socioeconômicos em relação a sua área verde. A investigação foi realizada no centro urbano de Cuiabá (MT), em que foram mapeadas as áreas conforme: renda per capita, renda por pessoa e valores lançados do IPTU. Todos os bairros foram analisados conforme os parâmetros citados, gerando mapas por temática e relacionamento por meio de cluster e outliers, a partir de técnicas de Sistemas de Informações Geográficas (SIG). Foi possível estabelecer relação ao poder aquisitivo, dada à conjuntura dos valores de imóveis e sua localização, de modo a apontar os pontos positivos e falhos na percepção de valores diretamente relacionado as áreas verdes urbanas da cidade.

Palavras-chave: Áreas Verdes Urbanas; SIG; Cuiabá.

\section{Spatial patterns of socioeconomic indices and its relationship with green area in urban center}

\begin{abstract}
The urban green areas exert numerous functions in the natural environment, especially in the urban, because in the context of cities are important for human wellbeing. The objective of this research was to establish a systematic index from the analysis of spatial patterns of socioeconomic information in relation to its green area. The investigation was carried out at the urban center of Cuiabá (MT), where the areas were mapped: per capita income, income per person and values released from tax. All the districts were analyzed according to the parameters cited, generating maps by thematic and relationship by means of cluster and outliers, from techniques of Geographic Information Systems (GIS). It was possible to establish relation to the purchasing power, given the conjuncture of the property values and its location, in order to point out the positive and flawed points in the perception of values directly related to the urban green areas of the city.
\end{abstract}

Keywords: Urban Green Areas; SIG; Cuiabá.

Topic: Conservação da Biodiversidade

Reviewed anonymously in the process of blind peer.
Received: 02/02/2018

Approved: 20/05/2018
Jonathan Anderson de Paula Caldas

Universidade do Estado de Mato Grosso, Brasil

http://lattes.cnpq.br/2162661428773452

jonathancaldas@unemat.br

Rosane Coelho da Silva Sales (iD

Universidade do Estado de Mato Grosso, Brasil

http://lattes.cnpq.br/3995082941328962

http://orcid.org/0000-0002-6455-3267

rosanesales@ig.com.br

Valdiney Vieira da Silva (iD

Universidade Federal de Mato Grosso, Brasil

http://lattes.cnpq.br/1163757918412085

http://orcid.org/0000-0001-6458-0591

valdiney207@gmail.com

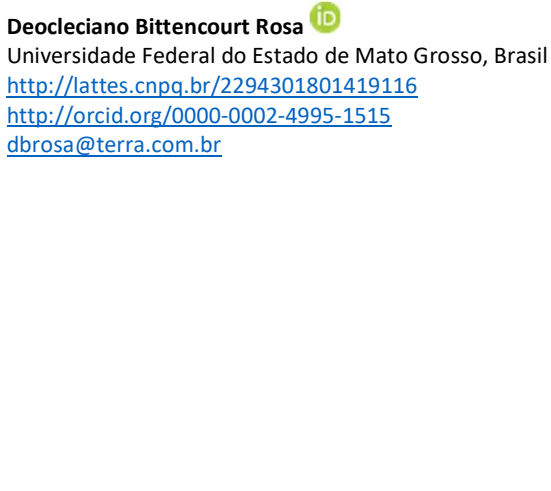

Referencing this:

CALDAS, J. A. P.; SALES, R. C. S.; SILVA V. V.; ROSA, D. B.. Padrões espaciais de índices socioeconômicos e sua relação com área verde de um centro urbano. Revista Ibero-Americana de Ciências Ambientais, v.9, n.1, p.1-12, 2018. DOI: http://doi.org/10.6008/SPC2179$\underline{6858.2018 .001 .0001}$

DOI: 10.6008/SPC2179-6858.2018.001.0001 


\section{INTRODUÇÃO}

Nas últimas décadas os problemas ambientais estão cada vez mais presentes no cotidiano urbano. Assim, as áreas verdes urbanas tornaram-se elementos importantes na defesa do meio ambiente pela sua degradação, e pela valorização do espaço que hoje lhes é destinado nos centros urbanos. Como, Moro (1976, p. 15) relata:

Que a constante urbanização nos permite assistir, em nossos grandes centros urbanos, a problemas cruciais do desenvolvimento nada harmonioso entre a cidade e a natureza. Assim, podemos observar a substituição de valores naturais por ruídos, concreto, máquinas, edificações, poluição etc., e que ocasiona entre a obra do homem e a natureza crises ambientais cujos reflexos negativos contribuem para degeneração do meio ambiente urbano, proporcionando condições nada ideais para a sobrevivência humana.

As áreas verdes urbanas exercem inúmeras funções no meio ambiente natural, mas, sobretudo, no ambiente urbano, pois, no contexto das cidades, são importantes para o bem-estar da população, contribuindo para melhorar a qualidade de vida nos seguintes aspectos: recreação, paisagismo, preservação ambiental, além de atenuar o calor do sol, absorver ruídos e aumentar a umidade do ar pela transpiração das plantas. Essas áreas servem também de escape nos finais de semana às pessoas que estão acostumadas a enfrentar uma longa jornada de trabalho diariamente, tráfego intenso nas grandes cidades, superlotações no transporte público, entre outras situações, diminuindo, dessa forma, o estresse da vida cotidiana.

O intenso processo de ocupação do seu sítio urbano gera situações de difícil reversão, tais como a supressão de áreas com cobertura vegetal natural, comprometendo os refúgios de fauna e flora; a impermeabilização excessiva do solo, potencializando os episódios de enchentes, de processos erosivos, de movimentos de massa, de perda de solo, de perda da qualidade dos mananciais de abastecimento, de alteração do clima da cidade, evidenciando a ocorrência de microclimas urbanos, dentre outros.

Em particular, as áreas verdes, aqui entendidas como sendo áreas com predomínio de vegetação, preferindo-se a presença de árvores, com funções ecológicas, de lazer e estéticas, com o predomínio de uso do solo permeável (sem concreto ou laje), com acesso irrestrito a toda a população e que deve propiciar condições para recreação. Estas características são evidenciadas e propostas por Cavalheiro et al (1999); Buccheri-Filho (2006); Buccheri-Filho e Nucci (2006). Estas áreas, portanto, podem ser consideradas cruciais para a qualidade de vida da cidade, porém sofrem com a sua drástica redução ou não da implantação em novos loteamentos, que envolve toda a cidade de Cuiabá.

As informações disponíveis, tanto no poder público, como em pesquisas acadêmicas, fundamentais para a proposição de políticas que visam reverter à situação detectada na cidade, encontravam-se dispersas e não sistematizadas. Neste trabalho objetiva-se em estabelecer um índice sistemático de informações socioeconômico para a cidade em relação a sua área verde. Isto é, não eliminasse a princípio todos os parques e jardins existentes, mas que evidenciasse a necessidade de melhoria das condições atuais dos parques, praças e jardins existentes e que estabelecesse novos parâmetros nas formações de novas áreas verdes. Estes princípios são evidenciados nos objetivos iniciais de proposta de criação destes espaços livres, que podem ou não se inserirem como áreas verdes. 
Inicialmente, é necessário discutir o que será contabilizado como áreas verdes urbanos. Na literatura pertinente ao tema deste trabalho, diversos autores trazem definições distintas sobre o que considerar como área verde. A definição que guia este estudo é oferecida por Demattê (1997), que define: "áreas verdes" acabam por ser um vocábulo que exprime diversos tipos de locações urbanas que têm em comum o fato de serem abertos e acessíveis à população, correlacionando-se à saúde e recreação, tanto ativa quanto passiva, proporcionando interação de atividades antrópicas com o meio ambiente.

Segundo Llardent (1982), áreas, zonas, espaços ou equipamentos verdes são espaços livres onde predominam áreas plantadas de vegetação, correspondendo, em geral, ao que se conhece como parques, jardins ou praças.

Cavalheiro e Del Picchia (1992) discutiram a existência do índice de $12 \mathrm{~m}^{2}$ de área verde/habitante considerado ideal, arraigado e difundido no Brasil e atribuído à ONU (Organização das Nações Unidas), OMS (Organização Mundial da Saúde) ou FAO (Organização das Nações Unidas para Agricultura e Alimentação) Os referidos autores afirmaram que esse índice não é conhecido por aquelas instituições e supõem que deve se referir somente às categorias de parques de bairro e distritais/setoriais, ou seja, áreas públicas com possibilidades de lazer ao ar livre. A Sociedade Brasileira de Arborização Urbana (SBAU) propôs como índice mínimo para áreas verdes públicas destinadas à recreação o valor de $15 \mathrm{~m}^{2} /$ habitante (SBAU, 1996).

O crescimento desordenado das cidades brasileiras e as consequências geradas pela falta de planejamento urbano, despertaram a atenção de planejadores e da população no sentido de se perceber a vegetação como componente necessário ao espaço urbano. Dessa forma, mais expressivamente, a arborização passou a ser vista nas cidades como importante elemento natural atuando como reestruturador do espaço urbano, pois as áreas bastantes arborizadas apresentam uma aproximação maior das condições ambientais normais em relação ao meio urbano que apresenta, entre outros, temperaturas mais elevadas, particularmente, nas áreas de elevados índices de construção e desprovidas de cobertura vegetal (CARVALHO, 1982, p. 63).

\section{MATERIAL E MÉTODO}

A cidade de Cuiabá está localizada no Centro Geodésico da América do Sul, na porção centro sul do estado, possui uma área territorial de $3.538,17 \mathrm{~km} 2$. No ano de 2014 possui 551.098 habitantes e está a uma altitude de 177 metros acima do nível do mar. A média das temperaturas é de 24 graus centígrados. A Grande Cuiabá, formada pela vizinha Várzea Grande é o portão de entrada não só para o Pantanal, mas também para Águas Quentes, Chapada dos Guimarães, Vila Bela da Santíssima Trindade e muitas outras belas regiões deste estado. São cidades-irmãs, unidas pelo rio Cuiabá.

Num contexto mais abrangente, constitui-se num entroncamento aéreo-rodoviário-fluvial interligando o norte do Brasil e o oeste da América do Sul (Bolívia e Peru). É também alternativa mais viável para a ligação portuária com o Pacífico através da Cáceres, San Matias, Santa Cruz de La Sierra e Portos do Chile e Peru. 


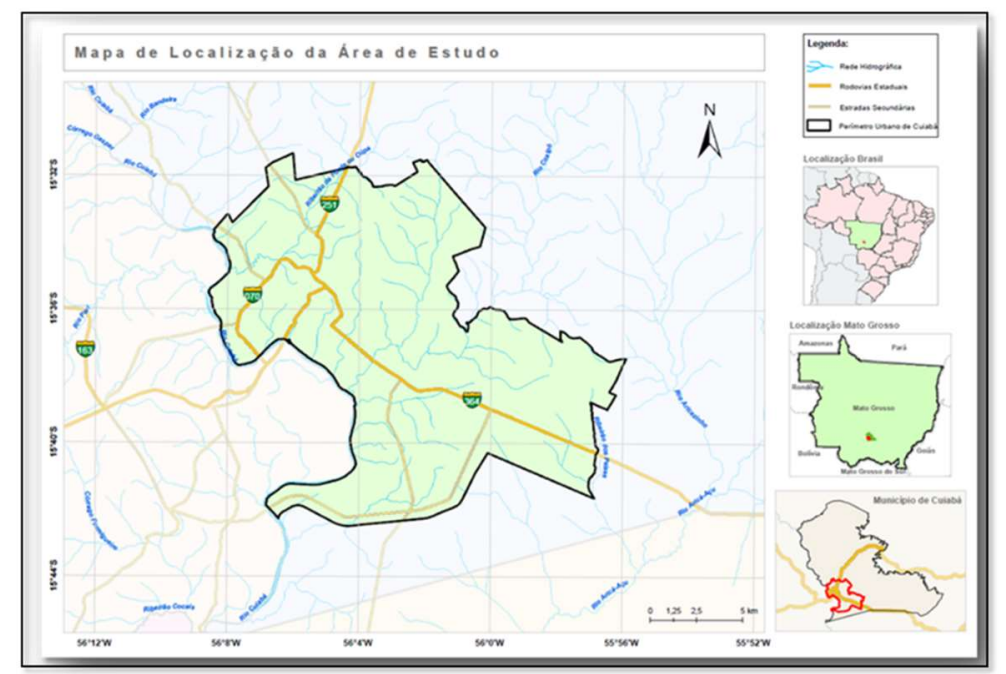

Figura 01: Mapa de localização do perímetro urbano da cidade de Cuiabá.

A capital mato-grossense limita-se ao norte com Rosário Oeste, a noroeste com Acorizal, a sudoeste com Várzea Grande ao sul com Santo Antônio do Leverger, a leste com Campo Verde e a nordeste com Chapada dos Guimarães.

Considerando a dinâmica territorial podemos considerar que os aspectos econômicos estão diretamente relacionados com a espacialização das áreas verdes legalizadas pelo Estado, já que muitas dessas áreas verdes não existiam pretensão econômica e por muito tempo ficaram as margens das políticas públicas.

Dentro do perímetro urbano de Cuiabá no ano de 2014, possuíam 195 bairros homologados pela Prefeitura Municipal de Cuiabá-MT, onde os dados referentes aos bairros foram retirados de várias fontes municipais, sendo que na base de lançamento do sistema arrecadação do IPTU da Prefeitura no ano de 2012, eles estão condensados em 117 bairros. Temos também as informações provenientes do IBGE, onde temos referenciados 115 bairros na capital. Para a equiparação desta pesquisa usamos como base as informações utilizadas pelo IBGE, sendo assim, condensamos os bairros conforme Quadro 02.

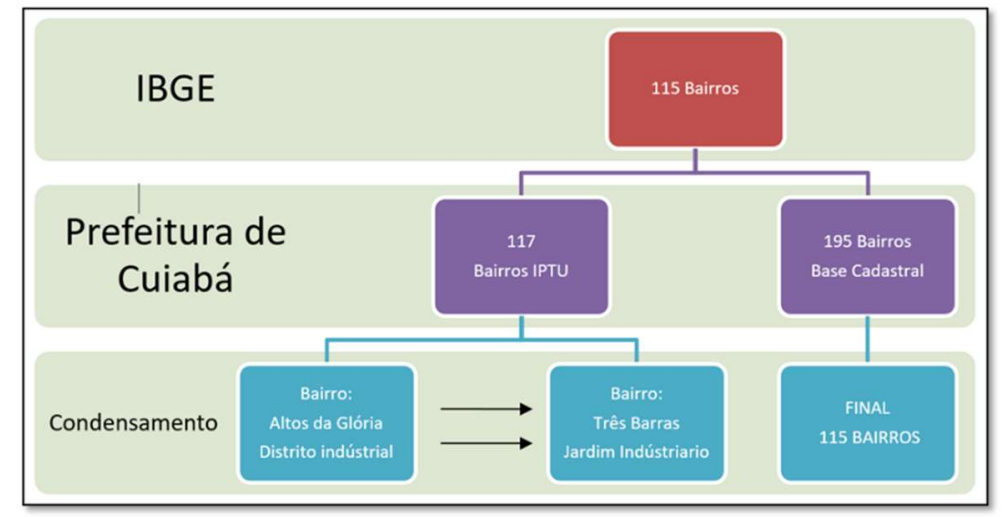

Quadro 01: Quadro demonstrativo da estrutura dos dados e seu esquema de condensação para equiparação dos dados para a análise.

Dos 195 bairros da base cadastral condensamos para 115 bairros utilizando como metodologia o seu vizinho mais próximo e a maior quantidade de habitantes em amostra do IBGE. Dos 117 bairros com dados de IPTU, foi condensado para os 115 bairros identificados pela IBGE. Nele foi importado os valores integrais 
de valor lançado do bairro Altos da Glória para o bairro Três Barras, e o bairro Distrito Industrial para o bairro Jardim industriário. Na figura 2 apresenta-se o croqui com os bairros condessados.

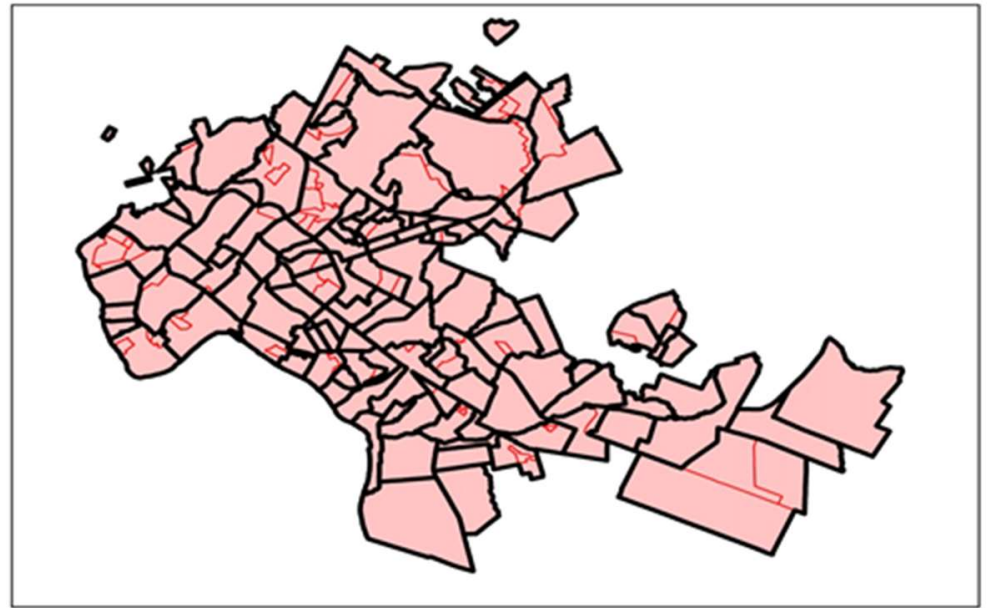

Figura 02: Croqui de condesamento dos bairros para análise.

O presente trabalho foi desenvolvido por meio de análise, representação e distribuição geográfica com aplicação de técnicas de geoprocessamento, utilizando o Sistema de Informações Geográficas (SIG). Foi utilizado o software ArcGis 10. Foram utilizadas técnicas de geoprocessamento com dados vetoriais homologados pela Prefeitura Municipal de Cuiabá e com dados alfanuméricos obtidos pelo Censo de 2010, elaborado pelo Instituto Brasileiro de Geografia e Estatística (IBGE). E, área verdes legalizadas do estado de Mato Grosso com dados vetoriais obtidos pela Secretaria de Estado e Meio Ambiente de Mato Grosso (SEMA). Com os dados parametrizados em produção e devidamente padronizados para estabelecimento de análises, foram todos adicionados em planilha do Excel com seus devidos valores. Abaixo exemplos da tabela analisada.

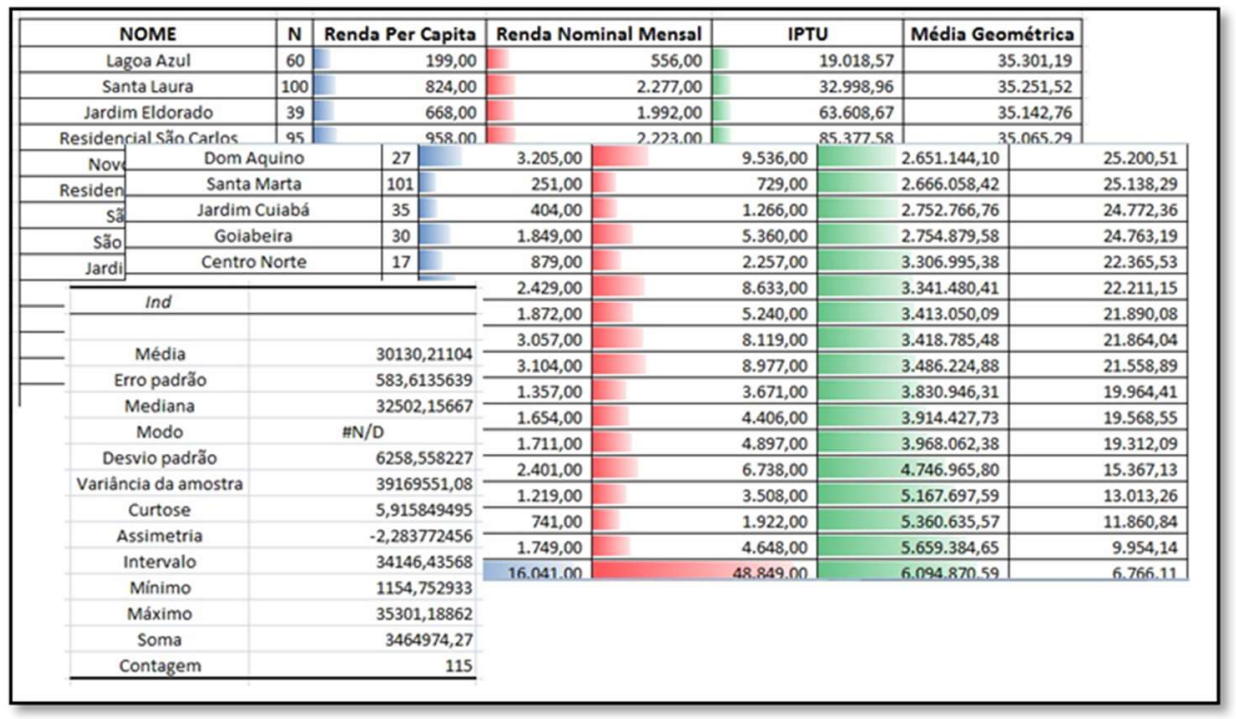

Quadro 02: Quadro demonstrativo da estrutura dos dados numa planilha com seus respectivos valores.

Logo após a condensação para a padronização e a inserção dos valores na planilha, foi possível integrar essas informações espacialmente na base vetorial de bairros da cidade de Cuiabá. Esta etapa foi elaborada a partir de 4 mapas temáticos: Mapa de Renda Per capita por bairro (figura 4), Mapa de Renda 
Nominal mensal por bairro (figura 5), Mapa de Lançamento de IPTU por bairro (figura 6) e Mapa dos Parques Estaduais na Cidade de Cuiabá. Assim, com os mapas elaborados foi possível elaborar um Mapa da média geométrica através de distâncias euclidianas (figura 7) descrito neste trabalho como mapa índice. Consiste na a junção dos três dados: renda per capita, renda nominal mensal e IPTU. Para a aplicação da média euclidiana foi criado um bairro irreal com os maiores valores observado entre os demais bairros e nele tiramos a diferença e elevando ao quadrado. A fórmula matemática utilizada foi:

$$
\left.\mathrm{D}=\sqrt[3]{\sum_{i=1}^{p}\left(x_{n}\right.}-x_{s l}\right)^{2}
$$

Onde:

$$
\begin{gathered}
D=\text { Novo índice } \\
X_{n}-\text { média renda nominal por bairro } \\
X_{s l}-\text { valor irreal, }
\end{gathered}
$$

Assim, foram repetidas três vezes os cálculos das médias e encontrado um novo índice (D), utilizando as médias geométricas com distância euclidiana. Com a média estabelecida foi elaborado o mapa com as três variáveis, desta forma aplicando técnicas de análise de cluster e clusters e outlier. Configurando assim mais dois mapas temáticos. Por fim, com o mapa de análise de cluster (figura 9) elaborado foi possível calcular a elipse de desvio padrão evidenciando o agrupamento, juntamente foi possível anexar as áreas de áreas verdes legalizadas pelo estado de Mato Grosso. O software utilizado para a elaboração destes mapas foi o ArcMap 10 da ESRI, nele, foram utilizadas as ferramentas de análise: Spatial autocorrelation (Morans 1); Clusters And Outlier Analysis (Anselin Local Morans 1); Cluster/Outlier Analysis with Rendering; Hotspot Analisys with Rendering; Directional Distribution (Standart Deviational Ellipse). A figura 3, a seguir mostra uma síntese do esquema metodológico utilizado neste trabalho:

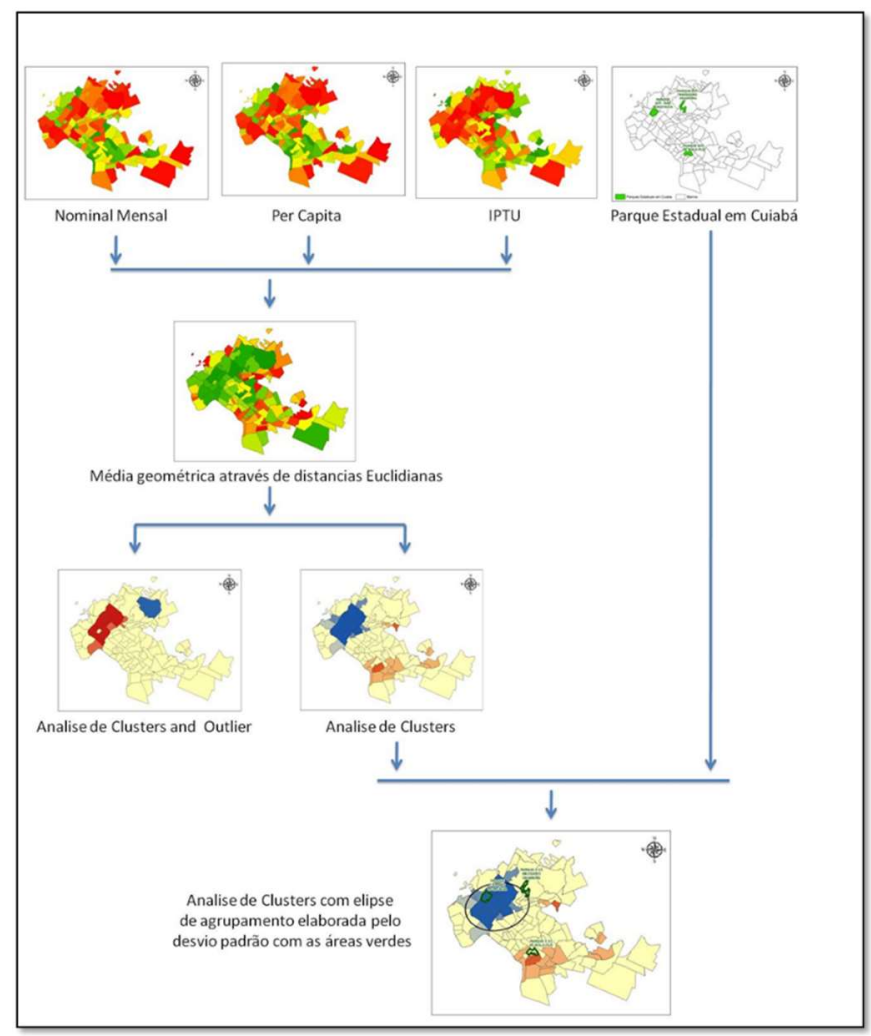

Figura 03: Síntese de Esquema metodológico para elaboração da pesquisa. 


\section{Análise Espacial}

As análises de padrões espaciais destes bairros de Cuiabá, a técnica utilizada foi de Análise de vizinhança, onde é mais conhecido como Análise de Clusters, ela é importante quando se dispõe de localizações exatas de eventos, e de um valor por área. Neste trabalho foi utilizado três indicadores/variáveis para elaboração final de um mapa índice dos bairros, que é o resultado da junção das três variáveis utilizando modelo matemático e gerando um único conjunto de dados.

As médias por bairros (índices) foram classificados entre si por ordem crescente e legendados com variações de cores do frio para o quente, ou seja, os bairros de alto rendimento em relação aos demais se constituem em cores quentes (vermelho, alaranjado para o amarelo) e para os bairros de baixo rendimento foi constituído em cores frias (Verde escuro, verde claro para o amarelo). $\mathrm{O}$ amarelo é a cor classificada como "intermediária".

Na figura 4 abaixo temos o mapa de faixas de renda per capita por bairro, onde foi utilizado técnicas de geoprocessamento como classificação condicionando os bairros de médias de baixo rendimento aos bairros de média de alto rendimento. Segue abaixo o mapa demonstrativo.

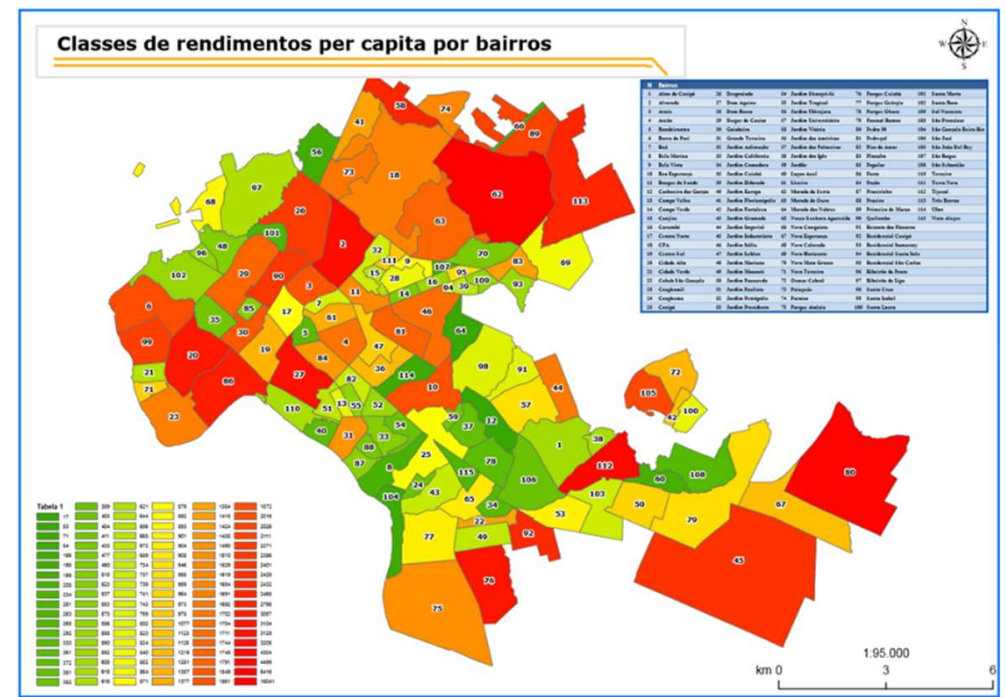

Figura 04: Mapa de classes da média de rendimentos da renda Per Capita por bairro da cidade de Cuiabá-MT.

Na figura 5 abaixo temos o mapa de faixas de renda nominal por pessoa por bairro, onde foi utilizado técnicas de geoprocessamento como classificação condicionando os bairros com a média baixa rendimento por pessoa aos bairros com a média alta de rendimento por pessoa. Segue abaixo o mapa demonstrativo.

Os indicadores de renda nominal e renda per capita são produtos de contagens realizadas pelo IBGE (CENSO2010). O IBGE fornece, para cada setor censitário, o número de chefes de família em cada uma das faixas de renda consideradas. Diversos indicadores de saúde e saneamento básico também são deste tipo, porém, não utilizamos nenhum dos dados referentes a isso. Ao longo deste trabalho o intuito inicial foi "mapear" os bairros de forma que fiquem classificados os padrões de socioeconômicos por bairros.

O processo da análise espacial segundo CÂMARA et al. (2002) compreende em um conjunto de procedimentos encadeados cuja finalidade é a escolha de um modelo inferencial que considere explicitamente o relacionamento espacial presente no fenômeno. 


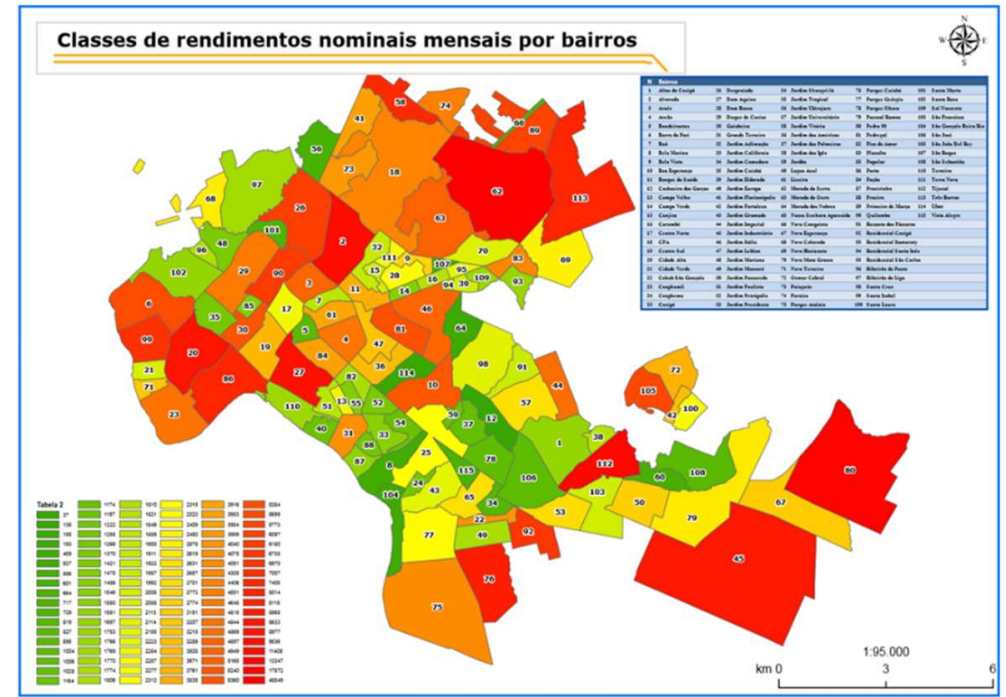

Figura 05: Mapa de classes da média de rendimentos nominais mensais por pessoa em bairros da cidade de CuiabáMT.

Na figura 6 abaixo temos o mapa de faixas de valores venais de IPTU por bairro, onde foi utilizado técnicas de geoprocessamento como classificação condicionando os bairros de lançamento da média de valores baixos ao lançamento da média de valores altos por bairros. Segue abaixo o mapa demonstrativo.

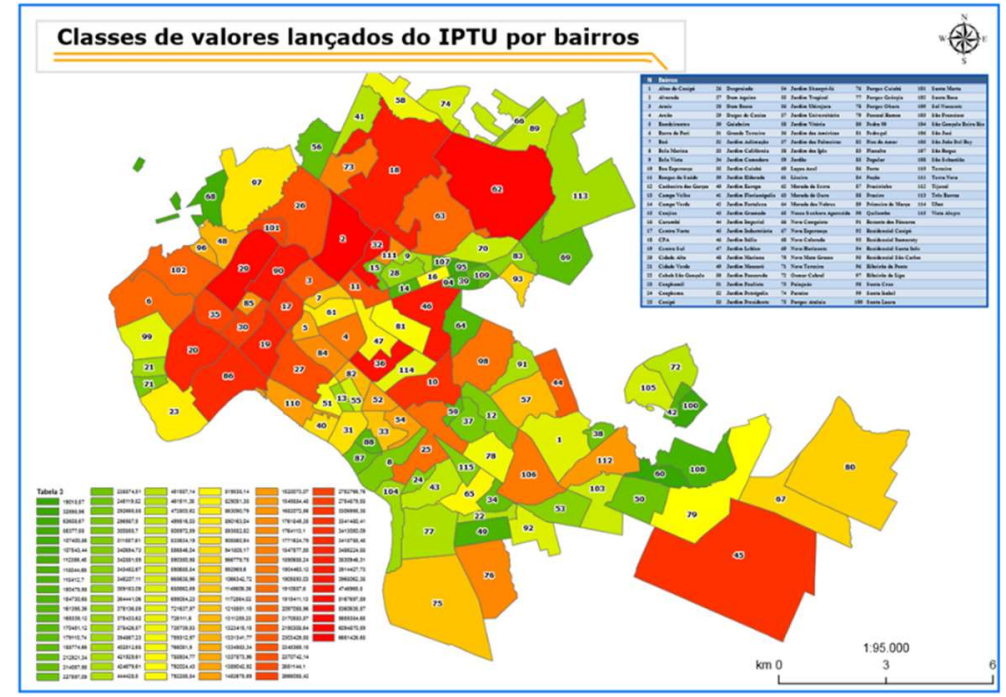

Figura 06: Mapa de classes da média de valores lançados de IPTU em bairros da cidade de Cuiabá-MT no ano de 2012.

Os procedimentos iniciais da análise incluem o conjunto de métodos genéricos de análise exploratória e a visualização dos dados, em geral através de mapas. Essas técnicas permitem descrever a distribuição das variáveis de estudo, identificar observações atípicas não só em relação ao tipo de distribuição, mas também em relação aos vizinhos e buscar a existência de padrões na distribuição espacial. Através desses procedimentos é possível estabelecer hipóteses sobre as observações, de forma a selecionar o modelo inferencial mais bem suportado pelos dados. A espacialização desses índices em um mapa geral (Mapa índice) é interessante e importante porque permite a captura de múltiplas dimensões em uma única realidade, revelando uma situação predominante. 


\section{RESULTADOS E DISCUSSÃO}

O primeiro mapa para a análise é o de rendimento per capita, demostrado na figura 4, fazendo uma análise com o mapa de rendimento nominal mensal (figura 5), foi observado que os dois "índices" são parecidos no quesito de valores e praticamente ficam nas mesmas faixas de uma variável a outra. Porém, nestes mapas no extremo nordeste da cidade de Cuiabá há um conjunto de bairros onde há uma percepção de alto rendimento. Juntamente com alguns bairros do centro norte da cidade. Nestes lugares há uma concentração de bairros de alto rendimento em relação aos outros bairros da cidade de Cuiabá. Inversamente ao sul da capital temos os bairros de baixo rendimento em relação aos demais bairros. Estes bairros estão espacializados geograficamente próximos ao rio Coxipó, observamos nos dois mapas que entre a média dos bairros de altos rendimentos e baixos rendimentos, há bairros de rendimentos intermediários próximos ao centro do perímetro urbano.

O mapa da média de valores lançamentos de IPTU por bairros (figura 6), nele verificamos mais homogeneidade referentes aos valores, apontados por bairros. Apesar do cálculo utilizado na confecção do mapa índice considerar uma média geométrica, neste mapa índice haveria uma grande probabilidade de ter características parecidas ao mapa do IPTU.

Com o cálculo dos valores utilizando médias geométricas com distâncias euclidianas foi verificado que o mapa índice (figura 7) também há características de homogeneidade bastante marcantes. É característico um grupo grande de bairros de alto rendimento em torno deles, como periferia os bairros de menos rendimentos. Alguns bairros próximos a "borda" no extremo sul do perímetro também têm se caracterizados com altos rendimentos. Isso se dá ao reflexo do plano diretor que indicou essas áreas com incentivos fiscais e com isenções de taxas para alavancar interesses a esses bairros para as indústrias, primeiro pelo fato de estar próximo a ao corredor de "entrada" de umas das principais rodovias vindo do sul do Brasil, BR-364. Esses bairros como o Distrito Industrial e Jardim industriário alavancou também os bairros adjacentes como a sua principal mão de obra elevando e dando condições para os seus habitantes. Neste mesmo mapa de índices é possível identificar que os parques verdes homologados pelo estado se localizam exatamente nestas áreas. Principalmente o Parque Estadual Mãe Bonifácia, que têm se a sua área de 77,16 Ha e tem se o Decreto de Lei número 1.470 de 09/06/2000, este parque está ligado à Secretaria do Estado e Meio Ambiente. Outro parque que toda a sua extensão está em áreas consideradas de alto rendimento segundo o mapa índice é o Parque Estadual Massairo Okamura que é na verdade uma Unidade de conservação também administrado pela Secretaria do Estado e Meio Ambiente, que tem se a sua área oficial de 53,75 hectares, com a sua base legal o decreto Lei número 7.506 de 20/09/2001.

Na figura 8, o mapa de clusters e Outlier já utilizados a técnica de clusters, que nada mais são os índices de auto correlação espacial. Aplicamos Índice de Autocorrelação Espacial Global de Moran (IGM) e Moran Map (MM). E com a aplicação desta auto correlação com o Mapa Índice foi possível verificar semelhanças de agrupamento (CLUSTERS) e também com esses índices foram constatados os Outlier que nada mais é algum bairro que despontou nos índices deixando para traz o grupo pertencentes, é 
imprescindível analisar que o bairro Aclimação teve um alto valor lançado pelo IPTU, por causa do Shopping instalado neste mesmo bairro. Neste mapa o Bairro Morada da Serra aparece como o outlier, pois, neste mesmo bairro estão incluídos todos os bairros conhecidos como CPA. Estes conjuntos de "bairros" formam um grupo a parte daquele que temos como principal Cluster, que neste mapa está apresentado de vermelho.

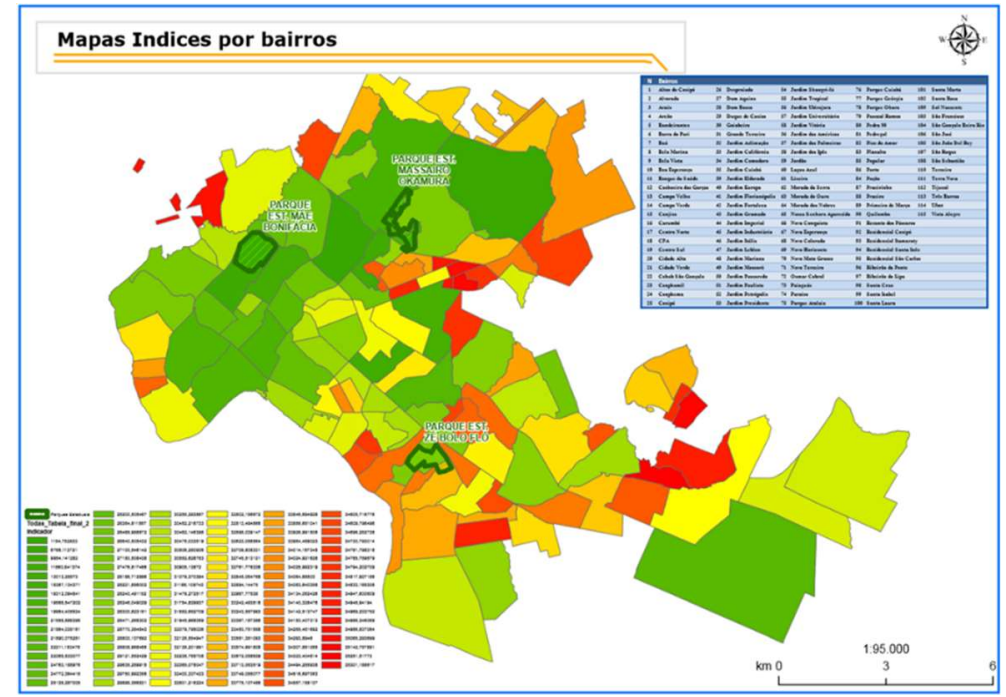

Figura 7: Mapa Índice (médias geométricas com distâncias euclidianas das variáveis da média por bairro de renda per capita do IBGE, média de rendimento mensal pessoal do IBGE e da média de valores lançados de IPTU em bairros no ano de 2012, com destaque as Área verdes Urbanas da cidade de Cuiabá-MT).

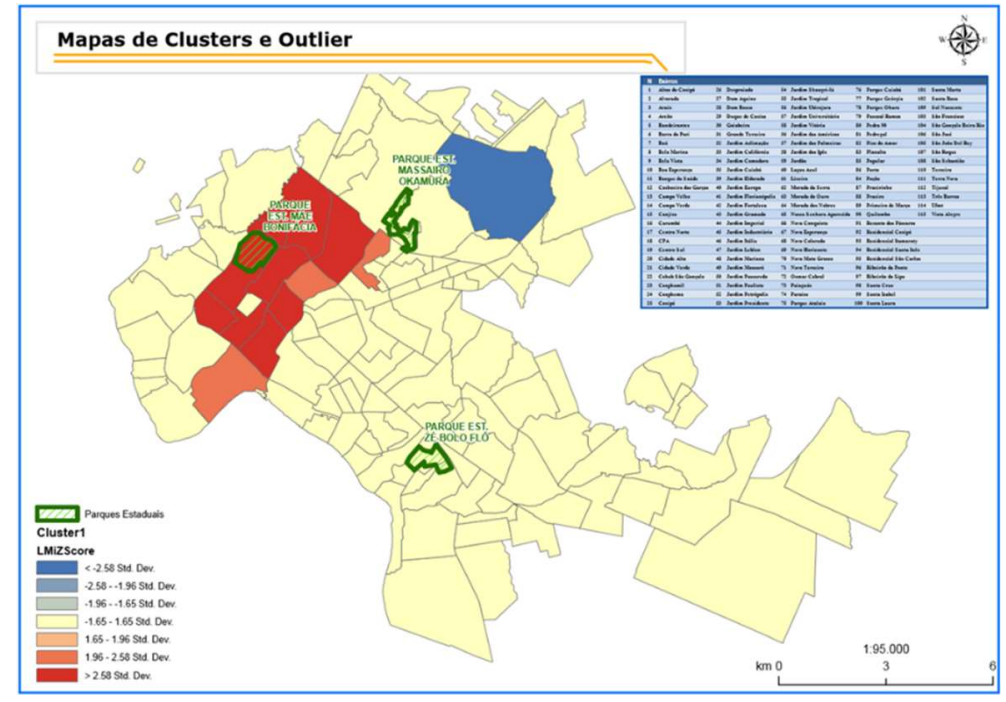

Figura 8: Mapa de Clusters e Outlier.

Este grupo ou Clusters é possível identificar principalmente ao mapa de Clusters (figura 9) que tem como seu principal grupo em azul localizado espacialmente no centro norte da Capital. Utilizando a técnica de calcular a elipse de desvio padrão observamos que todo esse grupo principal de azul está ao seu interior e fazendo um correlacionamento com as áreas verdes, podemos afirmar que os dois principais parques verdes da capital estão neste grupo de alto rendimento. Sendo que o terceiro parque o Parque Estadual Zé Bolo Flô apesar de ficar numa região próxima aos clusters de rendimentos baixos, a sua área está localizada num grupo intermediário. O parque estadual Zé Bolo Flô é administrado pela SEMA e tem se como sua área oficial de 66,40 hectares e na sua base legal o decreto lei número 1693 de agosto do ano 2000. 


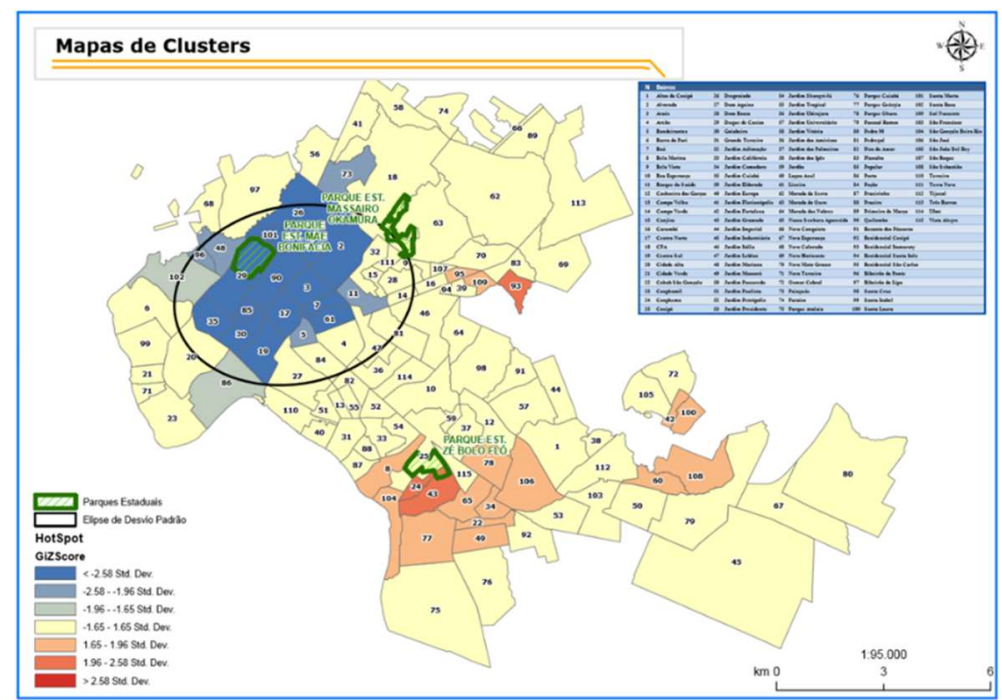

Figura 9: Mapa de Clusters e Outlier.

A dependência espacial é uma característica intrínseca aos dados espaciais (Câmera ET al, 2001). Sendo assim, para a validação completa do mapa Índice é necessária uma análise comparativa dos índices de autocorrelação espacial global e local. Em relação aos parques que estão "bem" distribuídos espacialmente temos uma relação com as áreas de alto rendimento. Podemos então considerar que dentre vários fatores esses parques contribuíram para a elevação desses rendimentos ou então esses lugares sofreram pressão publica param ser legalizadas e para não haver grilagem nestas áreas trazendo assim "problemas" de aspectos urbanos. Fazendo uma relação como um todo é importante ressaltar que as áreas verdes essencialmente estão localizadas $2 / 3$ em áreas de Alto rendimento e outro $1 / 3$ dele em áreas consideradas intermediárias. Analisando friamente a população de baixo rendimento ficam as margens dessas áreas verdes, havendo assim, não integração total da população urbana de Cuiabá com essas áreas verdes.

\section{CONCLUSÕES}

As geotecnologias representam um instrumento relevante para subsidiar a definição de políticas públicas, à medida que permitem analisar, produzir e integrar dados diversos na mesma base vetorial. A proposta de uso combinado de diversos métodos para a análise, aliada ao tratamento geográfico dos dados, evidenciou potencialidades até então escondida nas medidas tabuladas.

Essas pesquisas buscam ir além de simples espacialização de mapas temáticos para o diagnóstico das áreas de agrupamento, utilizando-se a média geométrica pode ser um instrumento potencial para um melhor acompanhamento da movimentação dos índices expressos no território, auxiliando não apenas o planejamento, mas também o monitoramento dos resultados de políticas públicas e intervenções no espaço urbano. Com os resultados analisados é perceptível numa primeira análise identificar que as áreas verdes não são integradas para o uso de toda a população, apesar de estar bem distribuídos espacialmente em relação ao perímetro urbano. Este tipo de pesquisa visa subsidiar os gestores das cidades para melhor gestão desses "aparelhos públicos verdes".

Assim, com estes dados obtidos é possível conhecer melhor o que tem nos "meandros" a cada bairro caracterizando as suas formas socioeconômicas e podemos supracitar que é influenciada a dinâmica 
territorial e o objetivo geral do Plano diretor é imprescindível dentro da gestão da cidade. As diferenças encontradas são fundamentais serem conhecidas para a redução dos desequilíbrios e consequentemente a redução das desigualdades socio territoriais.

\section{REFERÊNCIAS}

ARONOFF, S.. Geographic Information Systems: A

Management Perspective. Ottawa: WDL Publications, 1989.

BUCCHERI-FILHO, A.T.; NUCCI, J. C.. Espaços livres, áreas verdes e cobertura vegetal no bairro alto da XV, Curitiba/PR. Revista do Departamento de Geografia, UFPR, n.18, p.4859, 2006.

CALDAS, J. A. P.. Análise e Mapeamento das Áreas Verdes da Sede do Município de Cuiabá- MT, Utilizando Imagens de Alta Resolução Espacial. Dissertação (Mestrado em Mestrado em Geografia) - Universidade Federal de Mato Grosso, 2014

CAVALHEIRO, F.; DEL PICCHIA, P. C. D.. Áreas Verdes: conceitos, objetivos e diretrizes para o planejamento. In: Congresso Brasileiro sobre Arborização Urbana, 1. Anais. Vitória: 1992.

CAVALHEIRO, F.. Proposição de Terminologia para o verde urbano. Boletim Informativo da Sociedade Brasileira de Arborização Urbana. SBAU, v.7, n.3, 1999.
CARVALHO, M. E. C.. As áreas verdes de Piracicaba. Dissertação (Mestrado em Geografia) - Universidade Estadual Paulista, Rio Claro, 1982.

DEMATTÊ, M. E. S. P.. Princípios de paisagismo. 3 ed. Jaboticabal: UNESP, 1997.

LLARDENT, L. R. A.. Zonas verdes y espaços livres en la ciudad. Madrid: Closas Orcoyen, 1982.

MORO, D. Á. A.. As áreas vedes e seu papel na ecologia urbana e no clima urbano. Rev. UNIMAR, Maringá, v.1, p.1520, 1976.

PARK, R. E.. A cidade: sugestão para a investigação do comportamento humano no meio urbano. In: VELHO, O. G. O fenômeno urbano. 2 ed. Rio de Janeiro: Zahar Editores, 1973. p.26-57

A CBPC - Companhia Brasileira de Produção Científica (CNPJ: 11.221.422/0001-03) detém os direitos materiais desta publicação. Os direitos referem-se à publicação do trabalho em qualquer parte do mundo, incluindo os direitos às renovações, expansões e disseminações da contribuição, bem como outros direitos subsidiários. Todos os trabalhos publicados eletronicamente poderão posteriormente ser publicados em coletâneas impressas sob coordenação da Sustenere Publishing, da Companhia Brasileira de Produção Científica e seus parceiros autorizados. Os (as) autores (as) preservam os direitos autorais, mas não têm permissão para a publicação da contribuição em outro meio, impresso ou digital, em português ou em tradução. 